with the public sewer constructed over 30 years ago. Aberdare is in a fairly good sanitary condition, but here again there are a few congested areas along the river banks and here and there throughout the district will be found some back-to-earth and cellar dwellings without through ventilation. The water-supply is good and plentiful, being surface-collected and obtained from the Old Red Sandstone. Mountain Ash is a typical mining district situated in the same valley as Aberdare. The majority of the houses are of recent construction but there are several insanitary spots where the drains and sewers are defective and neglected. The water-supply, which is surface-collected, is good and plentiful.

Gelligaer and Rhigos district is situated in the Rhymney Valley on one side of the river and contains several typical mining villages, some of which are old. All the centres are sewered or being sewered. The water-supply is short during dry weather. Throughout the whole of this registration district there is no difficulty whatever in summoning medical aid. By far the majority of confinements are attended by unskilled and untrained midwives. On referring to Table XIV. it will be seen that the death-rates from puerperal fever and the accidents of childbirth are excessively high.

'The Bridgend registration district has an acreage of 110,571 ( 1.6 acres to each person) and is situated partly in the Vale of Glamorgan and partly in mining valleys of MidGlamorgan. It includes the old market town of Bridgend (population 6063), Cowbridge (1202), a small seaside resort called Porthcawl (1872), an extensive agricultural area, together with the mining districts of Maesteg $(15,012)$ and Ogmore and Garw $(19,907)$. These mining centres are situated in narrow valleys, especially the Garw, where some few years ago puerperal fever was epidemic. In these valleys there occurred an epidemic of this malady in 1892-93. To this I shall refer presently. Bridgend and the valleys above it are now being sewered but the river up to the present has been the sewer of the locality and its condition in all probability was associated with the perennial prevalence of typhoid fever at Bridgend. The water-supply for all these places is fairly satisfactory. The majority of confinements are attended by untrained and unskilled midwives and few only, except in the older towns, by medical men. There is but little difficulty in obtaining skilled medical assistance at short notice. On reference to Table XIV. it will be seen that the mortality from "puerperal septic diseases" is excessively high, while that from "accidents of childbirth" is above the average.

The Neath registration district has an acreage of 87,811 (1.2 acres to a person) and includes the old towns of Neath (population 13,732), Briton Ferry (6961). Aberavon (7553), Margam (9014), Glyncorwg (6450), and Neath rural district $(27,343)$, the last named being mostly rural in character but also containing several mining villages of recent growth. The sanitary condition of Aberavon, Briton Ferry, and Neath is unsatisfactory and there are a large number of courts, alleys, and areas in the two latter which are liable to become flooded and where the houses are overcrowded upon area and with persons. The water-supply is inadequate. The majority of confinements here are attended by unskilled and untrained midwives and there is no difficulty except in the outlying farmhouses in procuring skilled medical assistance at short notice.

Pontardawe registration district has an acreage of 34,000 (1.6 acres per person) and is conterminous with the Pontardawe rural district. It is much smaller in extent and population than the other registration districts, consequently the figures given, although extending over 20 years, are not quite so reliable. It includes several important industrial and mining centres and there are practically in it no congested areas. The water-supply is good and abundant and in nearly all instances the sewage is not stored in cesspools but taken away on land or disposed of otherwise. The death-rate from puerperal fever is below the mean for England and Wales, but that from accidents of childbirth is by far the highest in the county. Indeed, for one year, 1893, it amounted to $12 \cdot 2$ per 1000 , in 1900 to 85 , and in 1898 to $9 \cdot 4$, figures which almost approach those recorded in lying-in hospitals about 100 years ago. I have no explanation to offer for this, for there is no difficulty in procuring skilled medical assistance at short notice. I may mention, however, that many young women are employed at the tinplate works.

The Swansea registration district has an acreage of $36,056(0.2$ acre per person) and comprises the county borough of Swansea (population 95,133) and the scattered mining and agricultural district of Llangyfelach $(29,989)$. The sanitary condition of the rural portion is far from being satisfactory and none of the populous mining centres are sewered. The water-supply is inadequate and un. satisfactory. There are no congested centres and but little overcrowding of persons. The majority of confinements are attended by unskilled and untrained midwives. The deathrates from puerperal fever and accidents of childbirth are considerably above the average.

The Gower registration district has an acreage of 41,110 ( 3.6 acres to a person) and includes the purely agricultural area of Gower (population 7266) and the small seaside resort of Oystermouth. There are no congested areas and the whole peninsula is a flat but undulating country. There is no difficulty in getting skilled medical assistance at short notice. Midwives attend the majority of confinements.

Below are given similar figures for the county boroughs of Cardiff and Swansea and the urban districts of Merthyr Tydfil and Rhondda, all situated in Glamorganshire in four different registration districts. The figures givtn extend over ten years.

TABLE XV.-Showing the Annual Death-rate per 1000 from Puerperal Septio Diseases and Aocidents of Childbirth for the County Boroughs of Cardiff and Swansea and tho Urban Districts of Khondda and Merthyr Tydfil during the period 1891-1900 (ten years).

\begin{tabular}{|c|c|c|c|c|c|c|c|c|c|c|c|}
\hline & \multicolumn{3}{|c|}{ Year. } & & & \multicolumn{2}{|c|}{ Rhondda. } & \multicolumn{2}{|c|}{$\begin{array}{l}\text { Merthyr } \\
\text { Tydfil. }\end{array}$} \\
\hline 1891 & $\ldots$ & ... & $\ldots$ & 0.06 & $4 \cdot 7$ & $3 \cdot 3$ & 3.0 & 6.0 & & 25 & $5 \cdot 9$ \\
\hline 1892 & $\ldots$ & $\ldots$ & $\ldots$ & 0.0 & $4 \cdot 6$ & $1 \cdot 8$ & $3 \cdot 1$ & $3 \cdot 8$ & & $3 \cdot 4$ & $7 \cdot 2$ \\
\hline 1893 & ... & ... & ... & 05 & $3 \cdot 8$ & $3 \cdot 6$ & $3 \cdot 0$ & 48 & & $9 \cdot 3$ & 4.4 \\
\hline 1894 & $\ldots$ & $\ldots$ & $\ldots$ & 0.6 & $2 \cdot 1$ & 1.6 & $5 \cdot 1$ & 45 & $\dot{g}$ & $3 \cdot 4$ & 3.9 \\
\hline 1895 & $\cdots$ & $\ldots$ & $\ldots$ & 0.18 & 1.6 & $1 \cdot 8$ & $2 \cdot 4$ & $2 \cdot 8$ & 8 & $3 \cdot 5$ & $3 \cdot 9$ \\
\hline 1896 & $\ldots$ & $\ldots$ & $\ldots$ & 0.5 & $2 \cdot 5$ & $1 \cdot 9$ & $4 \cdot 3$ & $4 \cdot 8$ & ב & $1 \cdot 2$ & $2 \cdot 5$ \\
\hline 1897 & $\ldots$ & $\ldots$ & $\cdots$ & 0.9 & 20 & $2 \cdot 0$ & $2 \cdot 3$ & $2 \cdot 4$ & 方 & $2 \cdot 4$ & 2.4 \\
\hline 1898 & $\ldots$ & $\ldots$ & $\ldots$ & $1 \cdot 6$ & 28 & $2 \cdot 3$ & $3 \cdot 4$ & 0.9 & & 1.6 & 6.0 \\
\hline 1899 & $\ldots$ & $\ldots$ & $\ldots$ & 0.9 & $2 \cdot 0$ & 03 & $3 \cdot 4$ & 39 & & $1 \cdot 6$ & $4 \cdot 2$ \\
\hline 1900 & $\ldots$ & ... & $\ldots$ & 0.7 & $4 \cdot 7$ & $4 \cdot 2$ & $2 \cdot 1$ & $2 \cdot 0$ & & $2 \cdot 2$ & 30 \\
\hline $\mathrm{Me}$ & & ... & ... & 0.59 & 3.0 & $2 \cdot 2$ & 3.2 & 35 & & $3 \cdot 1$ & $4 \cdot 4$ \\
\hline
\end{tabular}

A. = puerperal septic diseases. B. = accidents of childbirth. (To be continued.)

\section{THE LYMPHATICS OF THE LARYNX AND THEIR RELATION TO MALIGNANT DISEASE OF THAT ORGAN.}

By PHILIP R. W. DE SANTI, F.R.C.S. ENG., SURGEON TO THE THROAT, NOSE, AND EAR DEPARTMENTS, WESTMINSTER HOSPITAX.

Anatomy of the laryngeal lymphatics.-In nearly all textbooks on laryngology bat scant and imperfect notice is taken of the lymphatics of the larynx and of the subject of their involvement in malignant disease of that organ, yet the matter is one of considerable importance, not only from a pathological point of view but clinically with regard to prognosis, especially prognosis depending on operative treatment. A considerable amount of work has, however, of late been accomplished by anatomists in this field and it is the object of this paper to give an account of the most recent work on the lymphatics of the larynx and to discuss the anatomical facts in their relation to the spread of malignant disease of the larynx to the lymphatic glands. Apparently the first really accurate description of the laryngeal lymphatics was given by Teichmann who particularly drew attention to the distribution of the terminal vessels in the mucous membrane of the larynx. Sappey's (1874) well.known researches on the lymphatics completed the description of these vessels and described the general arrangement of the laryngeal lymphatic radicles, 
their continuation in the lymphatic channels, and final distribution to the glands. In 1887 Poirier $^{1}$ investigated the distribution of these lymphatics and pointed out that whilst most anatomists were agreed as to the presence of two regions in the largnx essentially different as regards the number and importance of the lymphatic vessels, the one supraglottic in the mucous membrane of which there is a rich network of lymphatics, and the other subglottic in which the lymphatics are particularly small and the meshes few, this condition becoming more accentuated as one follows them down towards the trachea, yet the intervening region, that practically of the true vocal cords, had not been adequately investigated.

The results of Poirier's injections of the lymphatics of the larynx may be summed up as follows. 1. As the lymphatic network in a subglottic injection is traced upwards it appears to end abruptly about one millimetre from the free border of the inferior or true vocal cords. 2 . In a supraglottic injection the lymphatic system as it invades the superior vocal cords is found also to become altered; though lymphatic radicles traverse the superior cords, still they are found to become more and more attenuated as they reach their free border. 3. The lymphatics of the true vocal cords, although difficult to inject, are found to be present but only in small numbers and of small size. Poirier also found injections of the subglottic region difficult and increasingly difficult the greater the age of the patient. Most of his successful injections were made in larynges taken from children from one to seven years of age. On the rare occasions in which he was able to inject the lymphatics in old people he found the mucous membrane of the larynx much less thick than in children and adults and he concluded that there was a progressive atrophy normally of the lymphatic system in the larynges of old people and that this attenuation and atrophy not only applied to the laryngeal mucous membrane but also to the lymphatic ducts that go to the neighbouring glands. Most (1899) applied in the study of the laryngeal lymphatics the method of Gerota and recently Ounéo ${ }^{2}$ has published an article giving his results, his conclusions being based on the results he obtained by injecting several larynges in the same manner as Most and confirming Most's results. I have personally also made some injections of the laryngeal lymphatics by Gerota's method and find that the results substantially agree with those of Poirier, Most, and Cunéo. Gerota's method of injection is as follows. Two grammes of Prussian blue to which three grammes of pure spirit of turpentine have been added are rubbed down in a mortar; 15 grammes of sulphuric ether are added and the whole filtered through a double layer of linen. The solution must be used at once for injection. The injection should be made with a syringe holding from 10 to 20 cubic centimetres. To the end of the syringe is fixed a small adjustment which receives the glass needle for puncturing the tissues. The larger end of the glass needle is wrapped round with a waxed thread to prevent leakage. The point is drawn out in the flame ; it must not be too fine or yet too thick. The mixture is injected into the tissues under low pressure only. By this method a much better knowledge of the lymphatics of certain parts of the body unsuitable for injection by mercury has been obtained.

Cunéo's account of the lymphatics of the larynx; the lymphatic radicles. - The lymphatics of the larynx originate in a network that covers the whole of the internal surface of the larynx and is densest where the mucous membrane is thickest. It is divisible into two areas, a superior and inferior. The superior area in which the terminal meshwork is very dense and easy to inject includes all the portion of the laryngeal mucous membrane above the glottis, epiglottis, aryteno-epiglottidean folds, inter-arytenoid region, and superior vocal cords. (In my injections I found an alteration in the number and size of the lymphatic radicles in the superior vocal cords-they became less in number and smaller in size as they approached the free border of the superior cords; these results agree with those of Poirier.) The inferior area includes the mucous membrane of the larynx below the glottis. At this level the network is less dense and in all cases more difficult to inject than that of the superior area. These two areas are relatively independent of one another. They are, as a matter of fact, separated by an intermediary zone formed by the inferior true vocal cords, at which level the lymphatic radicles are even more rare and attenuated, although not entirely absent. At the level of the posterior wall of the larynx the two areas extend without any very clear line of demarcation. If an injection at the level of the inferior true vocal cord be pushed the material injected enters the vessels of the superior network. The lymphatics of one-half of the larynx do not communicate with those of the opposite side along the anterior median line but along the posterior median line the intercommunications are very numerous. The infraglottic meshwork is directly continuous with the tracheal network; there is no line of demarcation at all. Similarly the supraglottic meshwork is directly continuous with the network covering the mucous membrane of the pharynx and base of the tongue. The middle group of post lingual vessels receive vessels that come from the anterior surface of the epiglottis itself. All these facts are of importance from the point of view of the local spread of laryngeal carcinoma.

Distribution of the lymphatic channels arising from the lymphatio meshwork. - Fach of the two areas has a distinct set of efferent vessels. The trunks arising from the supraglottic network run towards the lateral parts of the epiglottis and ary-epiglottic folds and then pierce the thyro-hyoid membrane at the point of entry of the superior laryngeal artery. After piercing the thyro-hyoid membrane these collecting trunks divide into three sets : an ascending group of one or two in number which cross the bypoglossal nerve and end in a gland situated just below the posterior belly of the digastric muscle; a horizontal group which empties into the glands placed on the internal jugular vein at the level of the bifurcation of the common carotid; and a descending group ending in glands of the same chain at a lower level-namely, the middle part of the lateral lobes of the thyroid gland. Sometimes one or two small glands are found on the thyro-hyoid membrane itself, but they do not apparently receive lymphatics from the larynx itself-their afferent vessels come from the lateral aspects of the pharyngo-larynx.

The efferent vessels of the infraglottic region are divisible into two groups-one anterior, the other posterior. The anterior group (supracricoid) consists of from three to four trunks which pierce the crico-thyroid membrane near the mid-line. Some of these trunks end, according to Poirier, in the prelaryngeal glands, others in a pretracheal gland, and still others in one of the glands of the middle or inferior sterno-mastoid chain (Most). The prelaryngeal and pretracheal glands form purt of a chain described as the deep anterior cervical chain (Poirier). This chain consists of three distinct groups or masses of glands. 1. A prelaryngeal lot first noticed by Engel the existence of which has been confirmed by the work of Poirier who found the group present 49 times out of 100 . Usually only one gland is present, which in the adult is of about the size of a pea and tends to atrophr in old age. It is found generally in the middle of the $\mathbf{V}$-shaped space formed by the two crico-thy roid muscles, though occasionally it is overlapped by the inner border of one of these muscles. In one out of six cases a second gland of about the s'ze of a pin's head has been found at the level of the top of the $V$-shaped space. Occasionally a gland is found on the upper edge of the isthmus of the thyroid gland (Mascagni, Most, Roubaud), and rarely a gland in front of the thyroid cartilage close to its anterior border. 2. A prethyroidean mass situated in front of the isthmus of the thyroid; this group is but rarely present. 3. A pretracheal mass usually consisting of one gland of the size of a small pea and situated about one and a quarter centimetres above the sternal notch. There may, however, be more than one pretracheal gland.

The afferent vessels of the prelaryngeal glands are some of the lymphatics of the middle lymphatic pedicle of the larynx and those of the pretracheal come partly from the thy roid body and partly from the prelaryngeal glands. The efferent vessels from the prelaryngeal, prethyroidean, and pretracheal glands empty themselves into the lowermost glands of the sterno-mastoid chain.

The posterior $\mathrm{c} r$ infracricoid group consists of from three to five trunks which pass over the crico-tracheal fascia at the junction of the lateral and posterior aspects of the trachea. These trunks end in from two to five glands running parallel with the recurrent laryngeal nerve. These glands collect vessels from the thyroid body, the lymphatics of the inferior pedicle of the larynx, and the ressels from the cervical 
portion of the trachea and osophagus. Their efferent vessels end in the lowermost glands of the sterno-mastoid chain and supraclavicular glands and not in the mediastinal glands.

To sum up, the lymphatic channels emanating from the larynx empty themselves into the glands placed under the sterno-mastoid muscles, into the prelaryngeal glands, into the glands accompanying the recurrent laryngeal nerves, and additionally into the supraclavicular glands. The substerno-mastoid group of glands must be considered as the chief set of glands to receive finally the lymphatics of the larynx; the prelaryngeal, pretracheal, and recurrent groups are, as Cunéo remarks, simple glandular points placed as interruptors on the line of the lymph vessels going from the infraglottic area to the deeper group of sterno-mastoid glands.

Application of these anatomioal facts to the extension of malignant disease of the larynx by the lymphatics.-In the year 1850 Krishaber divided cases of malignant disease of the larynx into two classes, those of intrinsic and those of extrinsic origin. He applied the term intrinsic to those cases in which the primary site of origin was the true or false vocal cords, the ventricles, or the parts immediately below the true vocal cords (subglottic), and the term extrinsic to tumours arising in connexion with the epiglottis, ary-epiglottic folds, interarytenoid space, \&c. The reason of this division was a twofold one-pathological and clinical. He laid down the dictum that "as long as the cancer remains intrinsic there is no glandular enlargement; when it is extrinsic the glands ar infected." Schwartz uses practically the same termsnamely, "caviteires et marginaux." Cunéo, however, has quite recently suggested that Krishaber's statement is in correct and classifies malignant disease of the larynx as supraglottic, infraglottic, and glottic in origin. $\mathrm{He}$ believes this division to be scientifically correct and based not only on the arrangement of the laryngeal lymphatics, as already described, but on ascertained clinical facts as regards the tendency to lymphatic involvement. Cunéo considers Krishaber's classification and formula inconvenient "in that it includes under the same heading varieties behaving as regards glandular infection in very different ways. One would have to admit that epitheliomas attacking the superior vocal cords, which are very rich in lymphatics, involve the glands equally late as in epitheliomas attacking the inferior vocal cords, the lymphatics of which are extremely few and ill-developed." He goes on to state that he has seen and collected cases showing that glandular infection occurs early when the superior vocal cords are the site of origin of laryngeal cancer. Accordingly, he suggests the following modification: "Glandular infection is more certain and more extensive in supraglottic cancer than in glottic or subglottic cancers." To my mind Cunéo fails to make out a sufficiently clear case for the abandonment of Krishaber's well-known classification and formula.

Although admitting the anatomical fact that injection of the laryngeal lymphatics shows that the lymphatic network is better marked in the area of the superior vocal cords than in the subglottic and glottic regions of the larynx, yet his statement that clinically there is a tendency to early implication of the glands in cases of carcinoma originating in the superior vocal cords is open to question and is most decidedly not borne out by the experience of most English laryngologists. On the contrary, those who have had most experience of malignant disease of the larynx in this country, such as Semon, Butlin, and others (and these two have had an experience second to none), have found that there is no more tendency to early infection of the glands when the disease originates in the false vocal cords than when attacking the true vocal cords or subglottic space. Is it not possible that Cunéo may be mistaken on this point on account of the undonbted fact that cases of malignant disease originating in the superior vocal cords may not for some length of time give rise to any obvious symptoms and therefore are not apt to come under notice until the disease is much advanced, whereas in malignant disease of the true vocal cords symptoms, especially hoarseness, are apt to be present in the earliest stage? This might easily account for Cunéo's conclusion as to early infection of the glands, for if two cases, one of cancer of the false vocal cords and one of the true vocal cords, were to be seen and diagnosed at the same stage, and that an early one, it would be found that in neither case were the lymphatic glands implicated. No; many years have now elapsed since Krishaber's classification and formula were adopted and clinical experience has only tended to prove that his classification is a correct one and that so long as malignant disease is limited to the interior of the larynx (intrinsic) glandular infection is rare, but that if the external parts of the larynx (extrinsic) be affected early glandular infection is the rule. There seem, therefore, no sufficient grounds at present to abandon Krishaber's division; no useful purpose would be served thereby and only confusion that already exists in abundance rendered worse confusion.

Extrinsic carcinomata all present certain characteristics tending to spread towards the upper opening of the larynx and the lateral parts of the pharyngo-laryngeal region. This progress is rapid and sure when the epiglottis or aryepiglottic folds are primarily attacked, less so when the arytenoid region is attacked. Although extrinsic carcinoma reaches the final stage of its evolution by invading the extralaryngeal parts it is particularly at the level of the posterior aspect of the thyro-hyoid membrane that it is liable to show itself externally -i.e., to ulcerate through. Extrinsic carcinoma tends to become arrested, at any rate for some time, in its growth downwards by the true vocal cords. Intrinsic carcinoma attacks most frequently the true vocal cords (29 out of 117 cases-Baratoux; 15 out of 55-B. Fraenkel, Semon), next in frequency the superior or false vocal cords, and last]y the subglottic region. Carcinoma of the true vocal cords is conspicuous by virtue of the slowness of its evolntion. It tends to spread at first towards the opposite vocal cord and later to the supraglottic region. Similarly when the superior vocal cords are attacked extension is towards the supraglottic region.

Subglottic carcinomata are rare ; out of 486 cases Sendziak only collected five. They tend to spread downwards and invade the trachea. Their growth upwards is usually checked by the true vocal cords, although in a case observed by Cunéo the true vocal cords were invaded, the parts above, however, being quite free. With the exception of malignant disease originating in the epiglottis or arytenoid region the disease tends to remain limited at its commencement to one-half of the larynz. Sooner or later, however, the neoplasm tends to attack the opposite side. A few cases have been reported in which the opposite side has become affected by contact, but usually it is by direct continuous invasion. This most often occurs at the level of the posterior aspect of the larynz, although it has been observed to invade the opposite cord through the anterior commissure (Semon). The distribution of the lymphatics can to a great extent explain these different particulars in the local extension of cancer of the larynz.

The arrest for a long time of growths reaching to the inferior true vocal cords is the result of the attenuation of, and diminution in the number of, the lymphatics at this point. In extending towards the superior laryngeal orifice and lateral aspects of the larynx extrinsic carcinoma only obeys the general law observable in the extension of all epitheliomas-namely, a preference to follow the course of the lymphatic stream. The connexion of the lingual lymphatics with those originating on the anterior aspect of the epiglottis explains the tendency to extension of malignant disease of the epiglottis to the base of the tongue. The continuity of the subglottic meshwork with that of the trachea equally accounts for the extension of subglottic cancer towards the trachea. The small number and ill-developed condition of the lymphatics of the inferior vocal cords account mainly for the slow evolution of epithelioma attacking that region. Finally, the relative independence of the lymphatics of each half of the larynx accounts for the non-involvement of the opposite side of that organ for a period at all events more or less lengthy.

Like all epitheliomata cancer of the larynx tends eventually to invade the lymphatic glands ; in fact, it is the rule in late cases. Schleier has noticed it 20 times out of 125 cases and Sendziak notes 54 cases out of 486 . It is only fair, however, to say that other observers give a much higher percentage-Juraz nine out of 21 and Schwartz 13 out of 28 cases. At the same time lymphatic infection is fairly rare if the growth be limited to the true or false vocal cords, particularly to the anterior two-thirds of the true cords. It is also uncommon in cases of subglottic origin. It is well to remember, as pointed out by Curéo, that enlargement of the glands in a case of epithelioma of the larynx does not necessarily mean malignant infection. The enlargement may be due to septic infection from a septic malignant alcer or to some septic lesion of the pharynx. Much more attention should be given in all cases of post.mortem examinations performed on patients dying from malignant 
disease of the larynx to the microscopic examination of the neighbouring lymphatic glands; in two cases lately under my care, both advanced cases of intrinsic carcinoma and in which ante mortem no infection of the glands could be made out, post-mortem examination microscopically of the cervical glands gave no evidence of secondary infection.

In cases of epithelioma of the epiglottis and ary-epiglottic folds very early glandular infection is the rule. I bave seen most extensive masses of fixed hard glands in such cases. The fact, nevertheless, remains that in many cases (intrinsic) glandular involvement occurs relatively late. Cunéo mentions several causes to explain this early immunity of the glands. First of all he points out that the major number of laryngeal carcinomata are squamous epitbelioma (248 cases out of 486 -Sendziak) and he goes on to state that it is well known that this variety of growth generally attacks the glands somewhat late. This, however, is certainly incorrect ; for instance, in epithelioma attacking the tongue or tonsil very early and extensive implication of the glands is the rule. Again, he thinks cancer of the larynx tends frequently to become pedunculated and to grow into the cavity of the larynx without extending much beyond the border of its base of origin and points ont that pedunculated cancers growing into a cavity do not as a rule invade the glands until a very late stage, a good example being papillary carcinoma of the bladder.

Whilst admitting that occasionally laryngeal epithelioma is pedunculated and may possibly for this reason not invade the glands until a late stage, yet in my experience it is exceptional to come across a case of laryngeal epithelioma that is pedunculated. Usually the neoplasm is sessile with a broad base of origin and much infiltration. The only rational explanation seems to me to lie in the distribution of the lymphatic meshwork of the larynx; if certain parts, such as the epiglottis and ary-epiglottic folds, are very rich in lymphatics and consequent glandular infection is both certain and early in appearing, it is seen that in other parts, such as the subglottic and less so the false vocal cords, the lymphatic meshwork is much less developed and that on the true vocal cords, one of the sites of election for epithelioma, the lymphatics are so few in number that their injection is a matter of considerable difficulty. In epithelioma attacking these parts glandular infection is as late in appearing as it is early when attacking the epiglottis or ary-epiglotic folds.

Distribution of glandular infection.-Bearing in mind the anatomical description of the glands already given one would expect infection to show itself in three groups of glands-the substerno-mastoid, the prelaryngo-tracheal, and the recurrent laryngeal. As a matter of fact all the glands included between the posterior belly of the digastric and the clavicle may become infected in cases of laryngeal cancer. There is nothing especially characteristic in their mode of invasion. Infection of the prelaryngo-tracheal glands is decidedly rare although Most has collected a few cases. Similarly only a few cases are on record of infection of the recurrent group (Juraz, Fraenkel, Bergeat, Manver, and Most). In all the verification has been post mortem, as malignant disease of these glands owing to their small size and depth cannot be recognised clinically. The order in which the glands become infected varies according to the site of origin of the growth. If of extrinsic origin it is particularly likely to occur in the upper group of glands of the sterno-mastoid chain, and if subglottic in the lower group. As a rule the gland which is first found to be enlarged and that is most often met with in intrinsic carcinoma is placed at the level of the anterior border of the sterno-mastoid muscle abont the height of the space which separates the hyoid bone from the thyroid cartilage (Schwartz). So long as the disease remains limited to one-half of the larynx glandular infection occurs only on the affected side. Most and Roubaud were unable to find a single case in which a unilateral laryngeal cancer had caused involvement of the glands on both sides. This is in strict accordance with the results of experimental research and of the pathological anatomy of the parts, for it has been already pointed out that an injection of the lymphatic meshwork of one half of the larynx, though occasionally able to cross the mid-line, never penetrates the lymphatic radicles of the opposite side. When, however, cancer attacks the mid-portions of the epiglottis or cricoid plate glandular infection on both sides of the neck may occur.

These particular points in the pathological anatomy of cancer of the larynx carry certain practical deductions. Firstly, in early intrinsic carcinoma of the larynx of limited extent the disease can most thoroughly be dealt with by the operation of thyrotomy (or laryngo-fissure). It is very necessary, however, to bear in mind two important points with regard to this operation: (1) that the disease is frequently more extensive than the laryngeal picture has shown it to be and therefore the consent of the patient must be obtained to go further if at the time of the operation it is deemed necessary and to perform nnilateral laryngectomy and (2) that the fact of having to remove small portions of the cartilages of the interior of the larynx as well as the affected soft parts does not justify the operation being called a "partial extirpation of the larynx" in contradistinction to the term thyrotomy. As Semon has pointed out, the difference between a real partial-that is to say, a complete or nearly complete-removal of one-half of the larynx and a thyrotomy with extraction of a small piece of the cartilaginous framework is so great, owing not only to the much more extensive nature of the operation for partial laryng ectomy but also to the nature and technique of the after treatment and dangers of complication, that the innaginary difference between a thyrotomy with simple extraction of the soft parts and a thyrotomy in which in addition to the extraction of the soft parts an insignificant piece of cartilage has also to be removed is ridiculous. Such cases must be reckoned in the category of simple thyrotomies. Secondly, in cases of extrinsic carcinoma or of intrinsic too extensive to be dealt with by thyrotomy the tendency of the disease to remain limited for a certain length of time to one half of the larynx justifies the performance of unilateral laryngectomy. The question as to the advisability of excising the neighbouring glands is one of great importance and unfortunately there is a considerable divergence of opinion on the matter. Out of notes of 298 partial or complete laryngectomies collected by Sendziak extirpation of the glands is only mentioned 25 times, a percentage of 8 . Cunéo whilst admitting the tendency to comparatively late invasion of the glands and the rarity of recurrence in the glands (five cases out of 110 partial and seven out of 188 total laryngectomies) considers this proportion-i.e., 4.5 per cent. in the former and 3.9 per cent. in the latter - sufficient to justify the systematic extirpation of the set of glands liable to infection in all cases of laryngeal cancer, whether enlarged or not. The operative results of English laryngologists do not warrant the recommendation to extirpate in all and every case of malignant disease the set of glands liable to infection.

The whole question seems to me to turn on two main points : (1) the site of origin of the disease; and (2) the stage in which the disease is diagnosed. If an epithelioma of the larynx of strictly intrinsic origin is seen and diagnosed in an early stage and whilst therefore it is of limited origin the operation of thyrotomy as carried out in this country by Butlin, Semon, and others is amply sufficient to eradicate the disease. In the absence of obvious glandular involvement experience has shown that there is no need to perform a set operation to remove the group of glands liable to infection. Both Butlin and Semon, who are warm advocates of the operation of thyrotomy for early intrinsic carcinoma of the larynx, have had most brilliant results-results unequalled in the surgery of cancer in other parts of the body. For instance, if one takes Semon's cases operated on by him between June, 1891, and July, 1898 we find he performed thyrotomy on 12 patients. Ten of these 12 patients have been completely and lastingly cured-a percentage amounting to 833 . In none of these cases was it deemed necessary to extirpate any glands. On the other hand, in much advanced cases of intrinsic cancer of the larynx which necessitate removal of onehalf of the larynx the corresponding glands should be removed whether they are felt to be enlarged or not. Also, in any given case of extrinsic origin, bearing in mind the certainty of early involvement of the glands, a set operation for their removal, whether enlarged or not, should always be the routine practice.

To sum up briefly this question one would agree with Cunéo that extirpation of the group of glands liable to infection should be systematically carried out in all cases of malignant disease of the larynx with the exception of those cases of intrinsic origin which are seen early, are of limited extent, and in which there is no clinical evidence of glandular infiltration.

Stratford-place, $\mathrm{w}$. 